\title{
A Mouse Model for Oral Mucositis Induced by Cancer Chemotherapy
}

\author{
YOSUKE SHIMAMURA ${ }^{1}$, ISSEI TAKEUCHI ${ }^{1}$, HIROSHI TERADA ${ }^{1,2,3}$ and KIMIKO MAKINO ${ }^{1,2}$ \\ ${ }^{1}$ Faculty of Pharmaceutical Sciences and ${ }^{2}$ Tokyo University of Science Center for Drug Delivery Research, \\ Tokyo University of Science, Chiba, Japan; \\ ${ }^{3}$ Niigata University of Pharmacy and Applied Life Sciences, Niigata, Japan
}

\begin{abstract}
Background: Oral mucositis (OM), one of the side-effects induced by chemotherapy, has $40 \%$ incidence and the incidence rate increases to approximately $100 \%$ in combination with radiotherapy. We describe OM in ICR mice induced using 5-fluorouracil (5-FU) and $20 \%$ acetic acid. Materials and Methods: We optimized the dose of 5-FU and $20 \%$ acetic acid and validated the efficacy of standard therapies for OM. Results: All mice developed OM after administration of 5-FU and $20 \%$ acetic acid. Application of Kenalog ${ }^{\circledR}$ reduced maximum ulcer area and the duration of spontaneous recovery in a dose-dependent manner. Conclusion: We succeeded in developing a mouse model of $O M$ induced by cancer chemotherapy. New drugs for OM induced by anticancer drugs can be evaluated simply by monitoring the WBC count in this mouse model. This model is expected to contribute to development of new drugs and elucidation of the mechanisms of ameliorating stomatitis as a side-effect of anticancer drugs.
\end{abstract}

Surgical treatment, chemotherapy, radiotherapy, and immunotherapy are the common means of cancer treatment (1). In chemotherapy, cancer cells are injured doing specific cellcycle phases (2). Normal healthy cells, such as oral epithelial cells, gastric epithelial cells, hematopoietic cells and root hair cells, are injured as well as cancer cells. As a result, such damage to normal cells leads to various side-effects such as oral mucositis (OM), diarrhea, immunosuppression, and hair loss (3).

One of the side-effects induced by chemotherapy, OM, is reported to have $40 \%$ incidence and the rate increases to

Correspondence to: Kimiko Makino, Faculty of Pharmaceutical Sciences, Tokyo University of Science, 2641, Yamazaki, Noda, Chiba 278-8510, Japan. Tel/Fax: +81 471213662, e-mail: makino@rs.noda.tus.ac.jp

Key Words: Oral mucositis, mouse model, chemotherapy. approximately $100 \%$ in combination with radiotherapy $(4,5)$. Direct mucous membrane damage and secondary infection in the mouth cause $\operatorname{OM}(3,6)$. The former is caused by reactive oxygen species produced as a result of anticancer drugs and the latter is due to immune depression based on myelosuppression (7). OM caused by anticancer drug treatment is exhibited as erythema, edema or ulceration that can be accompanied by alterations ranging from mild burning sensation to large and painful ulcers that have a wide range more than general stomatitis $(8,9)$. Symptoms such as eating and sleep disorders, communication difficulties, as well as the sharp pain, develop and reduce the patient's quality of life (10). It is also reported that loss of consciousness occurred due to deterioration of $\mathrm{OM}$ and forced cessation of treatment (11). Therefore, preventing symptoms of OM or treating it quickly brings improvement of a patient's quality of life, and reduces the need for treatment interruption. At present, various treatments (oral cryotherapy, brushing, administration of steroidal anti-inflammatory drug, disinfectant mouthwash, etc.) are used $(3,10)$ but they do not seem to be adequate and have little preventive effect (12). A novel drug for OM is needed. In order to develop new drugs, development of animal models is important.

Considerable attention has been paid to using hamsters or rats as animal models for the development of OM induced by anticancer drug treatment (13-16), radiation $(13,17,18)$, scratch wound (19) or application of acetic acid to the mucous membrane (14). However, hamsters and rats are not of low cost or easily handled. Moreover, institutions which have radiation equipment are limited. On the other hand, there are few reports on development of mouse models for $\mathrm{OM}$. Moreover to our knowledge, nothing has been reported on mouse models developed using acetic acid injection into the oral mucosa. Surprisingly, despite considerable research attention, no OM model leads to the development of appreciable ulcers in the oral cavity. In general, OM manifests as erythema, edema or ulceration that can be accompanied by alterations ranging from mild burning sensation to a wide range of large and painful ulcers. From 
this point of view, these OM models are irrelevant as mimics of OM induced by anticancer treatment.

In this study, we tried to prepare an OM animal model using mice in which OM was induced by direct application of acetic acid to their mucous membranes after treatment with the anticancer drug 5-fluorouracil (5-FU). Although 5FU has been widely used for the treatment of various cancer types, such as gastrointestinal, breast, and head and neck cancer (20-22), it causes OM as a side-effect. Most animal models of OM reported previously were induced by 5-FU (14-16). Furthermore, we evaluated the effectiveness of this model by measurement of the ulcerated area and white blood cell (WBC) count. The aims of this study were (i) to develop an animal model for OM induced by an anticancer drug with lower cost and easier handling than conventional models, and (ii) to produce appreciable ulcers to precisely estimate the effects of drugs for therapy of OM.

\section{Materials and Methods}

Animals. Nine-week-old male ICR mice, weighing 30-40 g, were purchased from Japan SLC, Inc. (Shizuoka, Japan). The animals were housed in groups of five per cage in a room maintained under standardized light $(12: 12 \mathrm{~h}$ light-dark cycle $)$ at an ambient temperature of $23 \pm 2^{\circ} \mathrm{C}$, humidity of $60 \pm 10^{\circ} \mathrm{C}$ with free access to food pellets and drinking water, and were acclimated for 7 days prior to use in experiments. The experimental protocol used in this study was in accordance with the guidelines of Tokyo University of Science (approval number Y14048).

Chemicals and drug preparation. Acetic acid (99.7\%) obtained from Wako Pure Chemical Industries (Osaka, Japan) was diluted to $20 \%$ with distilled water (Otsuka Pharmaceutical Co., Ltd., Tokushima, Japan). 5-FU obtained from Wako Pure Chemical Industries was chosen in this study, and diluted with distilled water to $8 \mathrm{mg} / \mathrm{ml}$. Turk reagent was obtained from Nacalai Tesque, Inc. (Kyoto, Japan). Isoflurane was obtained from Intervet Inc. (Millsboro, DE). Kenalog ${ }^{\circledR}$ was obtained from Bristol-Myers Squib (Tokyo, Japan). All other chemicals were of reagent grade.

OM induction. In order to replicate immunosuppression induced by anticancer drugs, mice were administered an intraperitoneal injection of 5-FU on days $-5,-3$, and -1 of the experiment at a dose of $30,40,50$, or $60 \mathrm{mg} / \mathrm{kg}$ body weight $(\mathrm{n}=5$ at each dose). Subsequently, on day 0 , under isoflurane anesthesia, the left cheek of the mouse was extended outside the oral cavity. Subsequently, mucosal ulcers were induced by injection of $20 \%$ acetic acid $(5,10$, 15 , or $20 \mu \mathrm{l})$ using a microsyringe with a $31-\mathrm{G}$ needle $(\mathrm{n}=5)$. In order to estimate this model's OM induced by 5-FU, the ulcerated areas of mice administered 5-FU and acetic acid were compared with those of mice treated only with acetic acid $(n=5)$.

OM treatment. In order to assess the usefulness of this model as a model of stomatitis, we prepared 20 mouse models under isoflurane anesthesia, then applied Kenalog ${ }^{\circledR}(15,20,25 \mu \mathrm{mol})$, an existing OM drug which is triamcinolone acetonide formulation, directly once daily after the acetic acid injections. This operation was carried

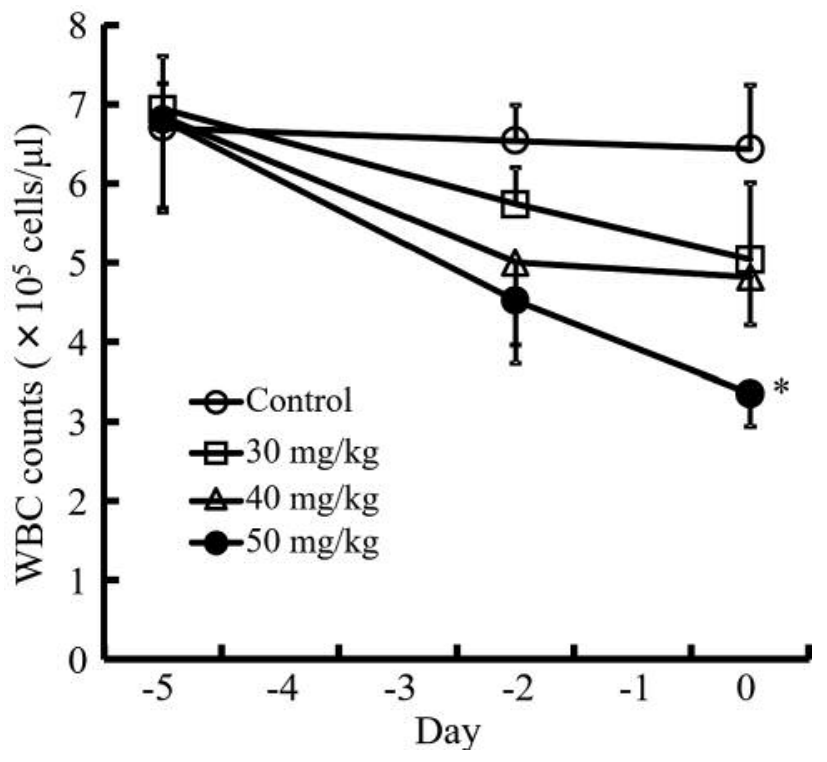

Figure 1. White blood cell (WBC) counts of normal healthy mice treated with 5-fluorouracil (5-FU) injection. Administration of 5-FU (30, 40, $50 \mathrm{mg} / \mathrm{kg}$ ) reduced the WBC count. Administration of $60 \mathrm{mg} / \mathrm{kg} 5-F U$ resulted in mouse death. We decided to administer 5-FU at a dose of $50 \mathrm{mg} / \mathrm{kg}$ body weight. Results are expressed as the mean $\pm S D$ in all groups $(n=5)$. Statistical analysis was conducted using Dunnet's method. Experimental conditions are described in the Materials and Methods. *Significantly different at $p<0.05$ compared with the control group (no 5-FU).

out until the end of complete healing. All mice recovered during the experimental period.

Assessments. From day 3 to the end of treatment, once every 2 or 3 days, the mice were anesthetized with isoflurane and the left cheek was inverted and the area of mucositis measured (as $\mathrm{mm}^{2}$ ) using image analysis software Image J (ACTREC, Navi Mumbai, India). Furthermore, the tail venous blood was collected, diluted in Turk's reagent and the WBC count in order to assess immunosuppression score.

Statistical analysis. Analysis of variance and multiple comparison tests using Dunnet's method, $t$-test, and Tukey's method were applied to determine differences. Data are expressed as the mean $\pm \mathrm{SD}$ and differences were considered significant at $p<0.05$.

\section{Results}

Efficient dose of 5-FU. The mice were dosed with 5-FU to induce immunosuppression as an anticancer drug side-effect. WBC counts decreased in a 5-FU dose-dependent manner (Figure 1). A significant difference between the control group and the group treated with $50 \mathrm{mg} / \mathrm{kg} 5-\mathrm{FU}$ was observed. However, the administration of $60 \mathrm{mg} / \mathrm{kg} 5-\mathrm{FU}$ resulted in death. Furthermore, even though mice adminstered 5-FU at 30,40 , or $50 \mathrm{mg} / \mathrm{kg}$ remained alive, OM was not induced. 

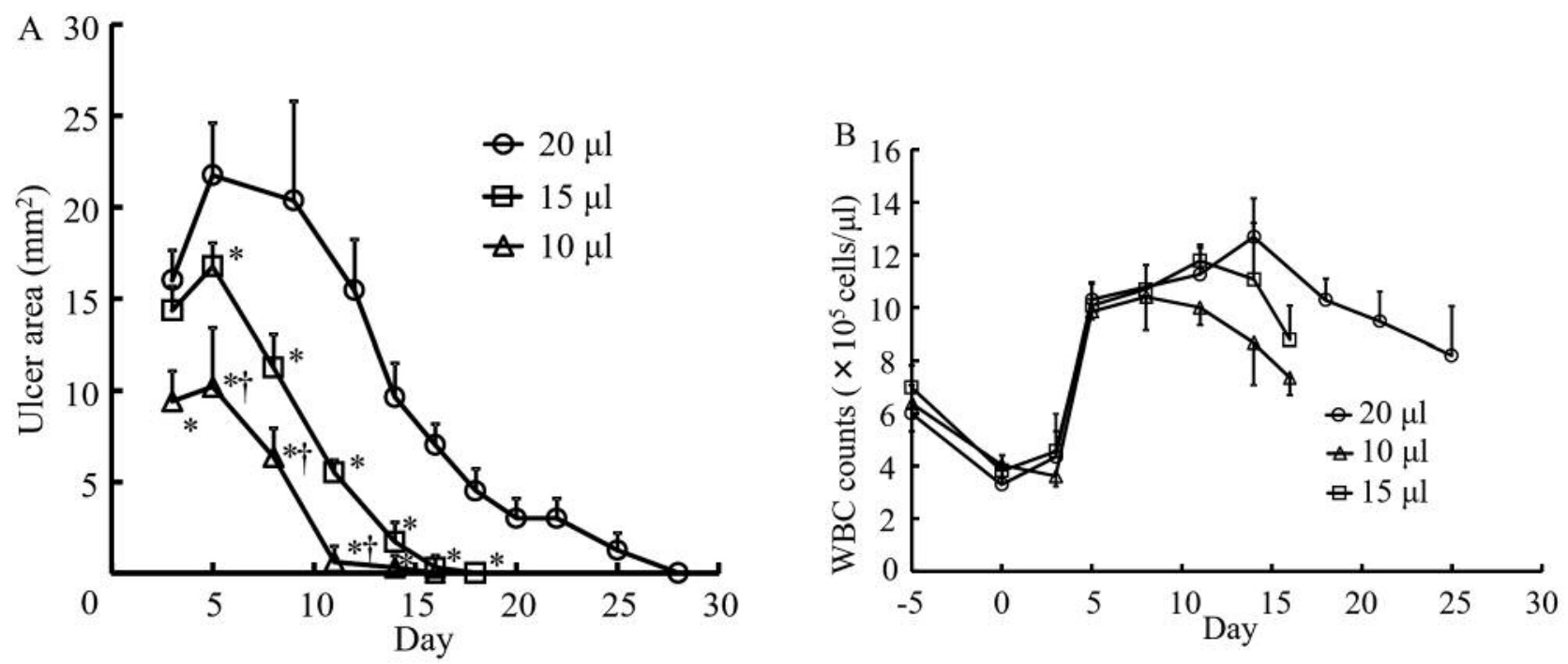

Figure 2. Efficacy of induction of oral mucositis (OM) in mice after 5-fluorouracil (5-FU) and acetic acid administration. The ulcerated area of $O M$ was measured $(A)$ and white blood cells $(W B C)$ were counted $(B)$. Mice were administered an intraperitoneal injection of 5-FU on days -5 , -3 , and -1 of the experiment at a dose of $50 \mathrm{mg} / \mathrm{kg}$ body weight. At intervals, the ulcerated areas were measured with calipers and the WBC count was made. Results are expressed as the mean $\pm S D$ in all groups $(n=5)$. Statistical analysis was conducted using Tukey's test. Significantly different at $p<0.05$ compared to administration of $* 20 \mu \mathrm{l}$, and $\dagger 15 \mu \mathrm{l}$ acetic acid. WBC counts did not significantly differ by dose.
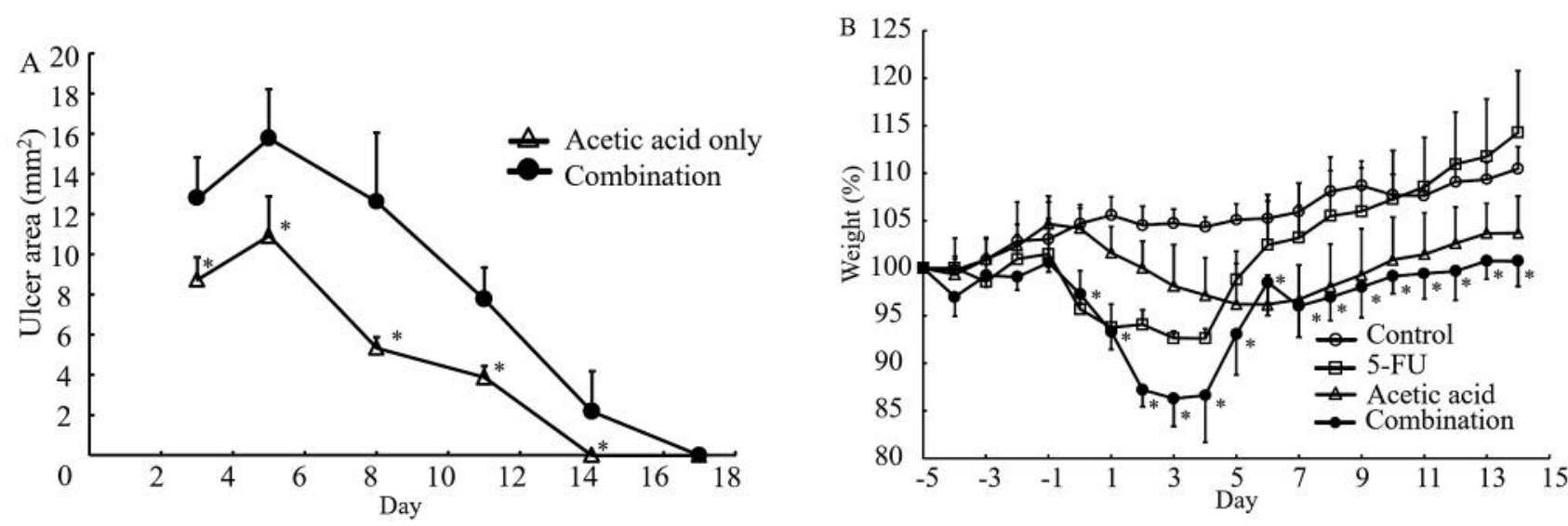

Figure 3. Effect of 5-fluorouracil (5-FU) treatment in a mouse model of oral mucositis (OM). OM was induced with application of acetic acid and mice were treated not with intraperitoneal injection of 5-FU on days -5, -3, and - 1 of the experiment at a dose of 30, 40, 50, or 60 mg/kg body weight. The ulcerated area was measured (A) and weight changes were calculated (B). Results are expressed as the mean $\pm S D$ in all groups $(n=5)$. Statistical analysis was conducted using $t$-test. *Significantly different at $p<0.05$ compared to the group treated with acetic acid only (A) or compared to the control group $(B)$.

Determination of the dose of acetic acid. We injected acetic acid to induce OM. The ulcerated area of mucositis became larger and the duration of spontaneous recovery became longer in a dose-dependent manner (Figure 2A). WBC counts were significantly increased after the administration of acetic acid and recovered to normal values with ulcer healing (Figure 2B).
Evaluation of the need for 5-FU administration. In order to confirm the necessity of 5-FU treatment, we produced OM using acetic acid only and using acetic acid plus 5 -FU. This experiment showed that 5-FU treatment enlarges the area of OM (Figure 3A). Furthermore, the body weight of mice given the combination of 5-FU and acetic significantly decreased compared to that in group treated with acetic acid 
only group on the day after treatment of 5-FU with acetic acid (Figure 3B).

Therapy with a pre-existing drug for OM. Application of Kenalog ${ }^{\circledR}$ reduced the maximum ulcerated area and the duration ofspontaneous recovery in a dose-dependent manner (Figure 4A). The body weight was also improved by administration of Kenalog ${ }^{\circledR}$ (Figure 4B). However, then WBC count significantly decreased below normal values (Figure 4C).

\section{Discussion}

In this study, we produced a mouse model of disease using 5-FU and acetic acid. Our aim was (i) to develop an animal model for $\mathrm{OM}$ induced by anticancer drug with lower cost and more safely and quickly than conventional models, and (ii) to produce appreciable ulcers to precisely estimate the effects of drugs. We succeeded in development of the model which fulfills the goals. This model is simple, inexpensive, and broadly applicable.

This model was administered 5-FU to mimic human OM. 5-FU-based animal models for OM are common models. 5-FU is an inhibitor of DNA synthesis and RNA function and damages cells undergoing active cell division such as cancer cells (2). However, normal cells in active cell division are similarly damaged. OM, one of the common side-effects of $5-\mathrm{FU}$, is caused by a decline of the mucosal barrier function due to myelosuppression and injury to mucous membrane cells of the mouth $(20,21)$. Several factors or genes contributing to 5-FU-induced mucositis have been studied (23-26).

WBC counts of mice administered $5-\mathrm{FU}(50 \mathrm{mg} / \mathrm{kg})$ were significantly reduced (Figure 1). This is important for the evaluation of immunity, and clearly shows 5-FU indeed induced immunosuppression.

Administration of 5-FU alone did not cause OM. In previous reports, animal models for 5-FU-based OM were induced not only by 5-FU but also by other stimuli (27). Therefore, we used acetic acid to induce OM. Using acetic acid, ulcers of almost the same size could be produced in all individuals. In addition, it was possible to clearly recognize the ulcer as shown in Figure 1B.

In previous clinical studies, it was reported that stomatitis as an anticancer drug side-effect continues for 1 or 2 weeks after anticancer drug treatment $(8,9)$. Figure $2 \mathrm{~A}$ shows administration of $15 \mu \mathrm{l}$ acetic acid induced OM which continued for 2 weeks. Therefore, we decided a dose of $15 \mu \mathrm{l}$ acetic acid was appropriate.

We demonstrated that the combination of 5-FU and acetic acid is effective in inducing $\mathrm{OM}$ in mice (Figure 3 ). Administration of a combination of 5-FU and acetic acid was effective at inducing OM in hamsters (14). However, such efficacy was not reported in mice.
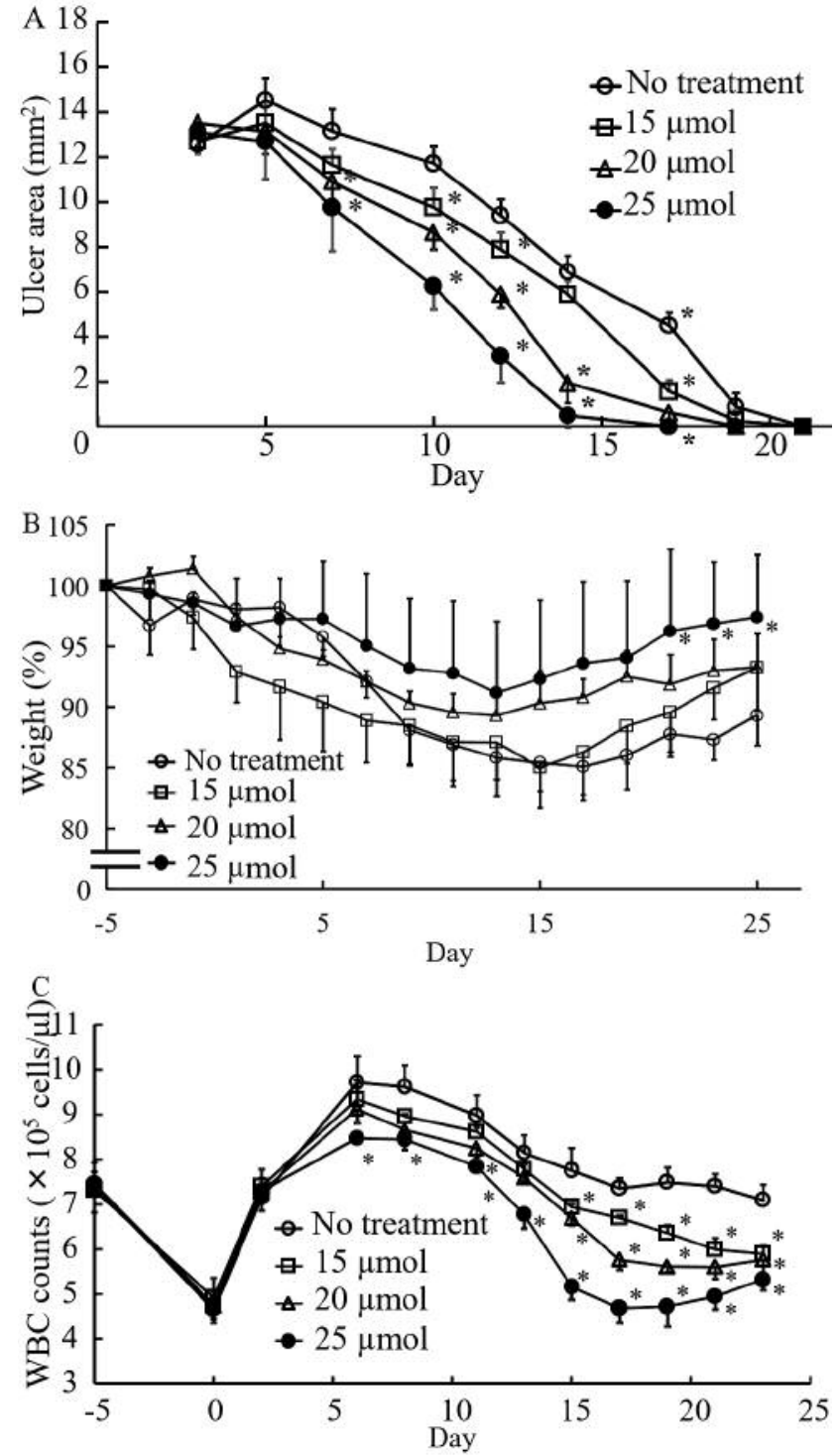

Figure 4. Model mice were treated by Kenalog ${ }^{\circledR}$ at different doses. The ulcerated area was measured (A), weight changes were calculated $(B)$, and white blood cells (WBC) were counted (C). Application of Kenalog ${ }^{\circledR}$ to mice with oral mucositis (OM) reduced the maximum ulcerated area and the duration of spontaneous recovery in a dosedependent manner. Kenalog ${ }^{\circledR}$ also brought rapid recovery of body weight. WBC counts of mice after treatment, however, decreased significantly compared to the group of mice not treated for OM. Results are expressed as the mean $\pm S D$ in all groups $(n=5)$. Statistical analysis was conducted using Dunnet's method. *Significantly different at $p<0.05$ compared to the group with no treatment for OM.

In the present study, we have shown that Kenalog ${ }^{(\mathbb{R})}$ is able to treat ulcers of the model mice (Figure 5A). Kenalog ${ }^{\circledR}$ is a triamcinolone acetonide, which is a steroid and has an antiinflammatory effect. 
The OM model induced by 5-FU and application of acetic acid in mice make it possible to estimate the therapeutic effect of new drugs on stomatitis objectively from the size of the ulcerated area and the period of ulcer healing, and to consider the safety of anticancer drugs from the number of leucocytes. This model has high reproducibility and ease of handling. It is expected that this model will enable histological analysis by using tissue sections to elucidate the mechanisms of ulcer healing more precisely. This model for OM induced by an anticancer drug will contribute to the development of new drugs for stomatitis induced by anticancer drugs.

\section{Conclusion}

We succeeded in the development of a mouse model of OM induced by cancer chemotherapy. This model can be easily produced and evaluated by measuring the ulcerated area and the duration of spontaneous recovery. The model enables us to consider if a new drug for OM is safe for using with an anticancer drug by monitoring the WBC count. This model should contribute to development and elucidation of the mechanisms of action of new drugs against stomatitis as a side-effect of anticancer drug therapy.

\section{Acknowledgements}

The Authors thank Mr. Hiroyuki Tanaka and Mr. Takehiro Shimonishi for helpful experimental support.

\section{References}

1 Zhang L, Yang X, Sun Z, Li J, Zhu H, Li J and Pang Y: Dendritic cell vaccine and cytokine-induced killer cell therapy for the treatment of advanced non-small cell lung cancer. Oncol Lett 11(4): 2605-2610, 2016.

2 Stuyver LJ, McBrayer TR, Tharnish PM, Hassan AE, Chu CK, Pankiewicz KW, Watanabe KA, Schinazi RF and Otto MJ: Dynamics of subgenomic hepatitis $\mathrm{C}$ virus replicon RNA levels in Huh-7 cells after exposure to nucleoside antimetabolites. J Virol 77(19): 10689-10694, 2003.

3 Lalla RV, Sonis ST and Peterson DE: Management of oral mucositis in patients with cancer. Dent Clin North Am 52(1): 6177, viii, 2008.

4 Panahi Y, Ala S, Saeedi M, Okhovatian A, Bazzaz N and Naghizadeh MM: Allopurinol mouth rinse for prophylaxis of fluorouracil-induced mucositis. Eur J Cancer Care 19(3): 308$312,2010$.

5 Rubenstein EB, Peterson DE, Schubert M, Keefe D, McGuire D, Epstein J, Elting LS, Fox PC, Cooksley C and Sonis ST: Clinical practice guidelines for the prevention and treatment of cancer therapy-induced oral and gastrointestinal mucositis. Cancer 100: 2026-2046, 2004.

6 Khan SA and Wingard JR: Infection and mucosalinjury in cancertreatment. J Natl Cancer Inst Monogr 29: 31-36, 2001.

7 Lopes-Serrao MD, Ussery SM, Hall RG 2nd and Shah SR: Evaluation of chemotherapy-induced severe myelosuppression incidence in obese patients with capped dosing. J Oncol Pract 7(1): 13-17, 2011.

8 Scully C, Sonis S and Diz PD: Oral mucositis. Oral Dis 12: 22941, 2006.

9 Chaveli-López B: Oral toxicity produced by chemotherapy: A systematic review. J Clin Exp Dent 6: e81-90, 2014.

10 Javadzadeh Bolouri A, Pakfetrat A, Tonkaboni A, Aledavood SA, Fathi Najafi M, Delavarian Z, Shakeri MT and Mohtashami A: Preventing and therapeutic effect of propolis in radiotherapyinduced mucositis of head and neck cancers: a triple-blind, randomized, placebo-controlled trial. Iran J Cancer Prev 8(5): e4019, 2015.

11 Hurria A, Browner IS, Cohen HJ, Denlinger CS, deShazo M, Extermann M, Ganti AK, Holland JC, Holmes HM, Karlekar MB, Keating NL, McKoy J, Medeiros BC, Mrozek E, O'Connor T, Petersdorf SH, Rugo HS, Silliman RA, Tew WP, Walter LC, Weir AB 3rd and Wildes T: Senior adult oncology. J Natl Compr Canc Netw 10(2): 162-209, 2012.

12 Bian L, Han G, Zhao CW, Garl PJ and Wang XJ: The role of SMAD7 in oral mucositis. Protein Cell 6(3): 160-169, 2015.

13 Shin YS, Shin HA, Kang SU, Kim JH, Oh YT, Park KH and $\mathrm{Kim} \mathrm{CH}$ : Effect of epicatechin against radiation-induced oral mucositis: in vitro and in vivo study. PLoS One 8(7): e69151, 2013.

14 Yoshino F, Yoshida A, Nakajima A, Wada-Takahashi S, Takahashi SS and Lee MC: Alteration of the redox state with reactive oxygen species for 5-fluorouracil-induced oral mucositis in hamsters. PLoS One 8(12): e82834, 2013.

15 Koohi-Hosseinabadi $\mathrm{O}$ andisheh-Tadbir A, Bahadori $\mathrm{P}$, Sepehrimanesh M, Mardani M and Tanideh N: Comparison of the therapeutic effects of the dietary and topical forms of Zizyphus jujuba extract on oral mucositis induced by 5fluorouracil: A golden hamster model. J Clin Exp Dent 7(2): e304-9, 2015

16 de Araújo AA, Varela H, de Medeiros CA, de Castro Brito GA, de Lima KC, de Moura LM and de Araújo Júnior RF: Azilsartan reduced TNF- $\alpha$ and IL-1 $\beta$ levels, increased IL-10 levels and upregulated VEGF, FGF, KGF and TGF- $\alpha$ in an oral mucositis model. PLoS One 10(2): e0116799, 2015.

17 Cotrim AP, Yoshikawa M, Sunshine AN, Zheng C, Sowers AL, Thetford AD, Cook JA, Mitchell JB and Baum BJ: Pharmacological protection from radiation \pm cisplatin-induced oral mucositis. Int J Radiat Oncol Biol Phys 83: 1284-1290, 2012.

18 Chen P, Mancini M, Sonis ST, Fernandez-Martinez J, Liu J, Cohen EE and Toback FG: A novel peptide for simultaneously enhanced treatment of head and neck cancer and mitigation of oral mucositis. PLoS One 11(4): e0152995, 2016.

19 Lee HR, Yoo N, Kim JH, Sohn KY, Kim HJ, Kim MH, Han MY, Yoon SY and Kim JW: The therapeutic effect of PLAG against oral mucositis in hamster and mouse model. Front Oncol 6: 209, 2016.

20 Waddell T, Verheij M, Allum W, Cunningham D, Cervantes A and Arnold D: Gastric cancer: ESMO-ESSO-ESTRO clinical practice guidelines for diagnosis, treatment and follow-up. Eur J Surg Oncol 40(5): 584-591, 2014.

21 Ajani JA, Bentrem DJ, Besh S, D’Amico TA, Das P, Denlinger C, Fakih MG, Fuchs CS, Gerdes H, Glasgow RE, Hayman JA, Hofstetter WL, Ilson DH, Keswani RN, Kleinberg LR, Korn WM, Lockhart AC, Meredith K, Mulcahy MF, Orringer MB, Posey JA, Sasson AR, Scott WJ, Strong VE, Varghese TK Jr., 
Warren G, Washington MK, Willett C, Wright CD, McMillian NR and Sundar H: Gastric cancer, version 2.2013: featured updates to the NCCN Guidelines. J Natl Compr Canc Netw 11(5): 531-546, 2013.

22 Longley DB, Harkin DP and Johnston PG: 5-Fluorouracil: mechanisms of action and clinical strategies. Nat Rev Cancer 3: 330-338, 2003.

23 Pritchard DM, Jackman A, Potten CS and Hickman JA: Chemically-induced apoptosis: p21 and p53 as determinants of enterotoxin activity. Toxicol Lett 102-103: 19-27, 1998.

24 Sonis ST, O’Donnell KE, Popat R, Bragdon C, Phelan S, Cocks $\mathrm{D}$ and Epstein JB: The relationship between mucosal cyclooxygenase-2 (COX-2) expression and experimental radiation-induced mucositis. Oral Oncol 40: 170-176, 2004.

25 Leitão RF, Ribeiro RA, Bellaguarda EA, Macedo FD, Silva LR, Oriá RB, Vale ML, Cunha FQ and Brito GA: Role of nitric oxide on pathogenesis of 5-fluorouracil induced experimental oral mucositis in hamster. Cancer Chemother Pharmacol 59: 603-612, 2007.
26 Logan RM, Stringer AM, Bowen JM, Yeoh AS, Gibson RJ, Sonis ST and Keefe DM: The role of pro-inflammatory cytokines in cancer treatment-induced alimentary tract mucositis: pathobiology, animal models and cytotoxic drugs. Cancer Treat Rev 33: 448-460, 2007.

27 Yoshino F, Yoshida A, Nakajima A, Wada-Takahashi S and Takahashi SS and Lee MC: Alteration of the redox state with reactive oxygen species for 5-fluorouracil-induced oral mucositis in hamsters. PLoS One 8(12): e82834, 2013.
Received September 10, 2017

Revised November 6, 2017

Accepted November 7, 2017 